\title{
Aislamiento de amebas de vida libre del género Acanthamoeba a partir de fuentes de agua en la ciudad de Ica
}

\author{
ROXANA SUÁREZ $\dagger^{1}$, YRMA ESPINOZA ${ }^{1,2}$, CARMEN VILLANUEVA ${ }^{3}$, JOSÉ RAMOS ${ }^{3}$, \\ PEDRO HUAPAYA ${ }^{2}$, RENZO MARQUINA ${ }^{1}$ \\ ${ }^{1}$ Facultad de Medicina, Universidad Mayor de San Marcos. ${ }^{2}$ Instituto de Medicina Tropical "Daniel A. Carrión". \\ ${ }^{3}$ Facultad de Biología, Universidad San Luis de Gonzaga-Ica. Perú.
}

\begin{abstract}
RESUMEN
OBJETIVO: Determinar la presencia del género Acanthamoeba en diversas fuentes de agua, en la ciudad de Ica, al sur de Lima. MATERIAL Y MÉTODOS: Se examinó 31 muestras de 7 fuentes de aguas naturales (lagunas) y 25 artificiales (pozos, tanques para terapia de rehabilitación, reservorios y cisternas) durante mayo de 1997, en diversos puntos de la ciudad de Ica. Las muestras fueron sembradas en Agar Myast y en Agar Napolitano, incubadas a $37^{\circ} \mathrm{C}$ y observadas a los 10 días. Las muestras positivas fueron inoculadas en ratones inmunocompetentes por vía intranasal, las lesiones producidas fueron cultivadas nuevamente siguiendo el mismo procedimiento. RESULTADOS: De las 31 muestras revisadas, en $11(35,5 \%)$, se observó quistes de Acanthamoeba, 6 fueron aisladas de fuentes naturales y 5 de fuentes artificiales, mientras que entre las muestras negativas sólo una provino de fuente natural y las otras 19 provinieron de aguas artificiales intradomiciliarias o del hospital local. Estos resultados permiten obtener un OR $=22,8$ para la exposición de fuentes naturales de agua, como causante de la infección (límite de confianza 95\% 1,83-642,55, $\left.\mathrm{X}^{2}=7,83\right)$. CONCLUSIONES: La presencia del género Acanthamoeba es más frecuente en fuentes de agua naturales en la ciudad de Ica, aunque es necesario realizar un estudio de mayor cobertura para confirmar esta situación.
\end{abstract}

Palabras clave: Ameba; acanthamoeba; contaminación del agua; contaminantes del agua; recursos hídricos.

\section{Acanthamoeba GENUS FREE-LIVING AMOEBAE ISOLATED FROM ICA CITY WATER SOURCES \\ SUMMARY}

OBJECTIVE: To determine the presence of Acanthamoeba genus in several Ica city (south of Lima) water sources. MATERIAL AND METHODS: Thirty-one samples from 7 natural water sources (lagoons) and 24 artificial sources (wells, tanks for rehabilitation therapy, reservoirs and cisterns) were examined during May 1997 in several points of the city. Samples were sowed in Agar Myast and in Agar Napolitan, incubated at $37^{\circ} \mathrm{C}$ and checked after 10 days. Positive samples were inoculated to immunocompetent mice by intranasal route; resultant lesions were cultured again following the same procedure. RESULTS: In 11 samples $(35,5 \%)$ Acanthamoeba cysts were isolated, 6 from natural sources and 5 from artificial sources; among negative samples only one came from natural source and the other 19 came from artificial sources inside homes or from the local hospital. OR $=22,8$ was obtained for exposition to natural sources of water, as cause of infection (confidence limit 95\% 1,83-642,55, X2 =7,83). CONCLUSIONS: Presence of Acanthamoeba genus is more frequent in natural water sources at Ica city. Further studies are necessary to confirm this situation.

Key words: Ameba; acanthamoeba; water pollution; water pollutants; water resources.

\section{Correspondencia:}

Pedro Ernesto Huapaya Herreros

Av. Oscar R. Benavides 5050, Dpto. 204

Callao 02, Perú

E-mail:pedro_huapaya@latinmail.com 


\section{INTRODUCCIÓN}

Las amebas de vida libre (AVL) son protozoos distribuidos mundialmente que se encuentran en distintos tipos de fuentes de agua, como lagunas, lagos, ríos, piscinas cloradas, océanos $\left({ }^{1-3}\right)$, así como, en la vegetación y suelos; también en los mamíferos, pescados y reptiles, en los cuales forman parte de su flora normal.

Algunos estudios han demostrado su presencia en los seres humanos, como parte de la flora normal, aislándoseles a partir de cavidades nasales, globos oculares y tubo digestivo. Dentro de este grupo de protozoos, existen 3 amebas importantes, por causar daño al hombre. Entre ellas tenemos, al género Naegleria, con la especie patógena al ser humano Naegleria fowleri, causante de la meningoencefalitis amibiana primaria (PAM) $\left({ }^{4}\right)$, enfermedad fulminante que ocurre en personas sanas que han tenido contacto con agua y que presentan como características temperaturas elevadas e insuficientes residuos de cloro libre.

Otra especie es Balamuthia mandrillaris, ameba oportunista, cuyo nombre se debe a que fue aislada a partir de mandriles. En 1990, Visvesvara la ubica dentro del género Leptomyxid, siendo reclasificada como Balamuthia en 1993. Esta ameba es la causante de la encefalitis granulomatosa y lesiones cutáneas, presentando una patología similar al género Acanthamoeba. Los casos que han sido reportados en América Latina (Perú, Argentina y México) están asociados con exposición a aguas de ríos o acequias $\left(^{5}\right)$.

El tercer género de importancia es Acanthamoeba, causante de diversas infecciones en el ser humano inmunocompetente e inmunosuprimido; no sólo es causante de la encefalitis granulomatosa amibiana $\left({ }^{4}\right)$, sino también de infecciones oculares, principalmente en individuos usuarios de lentes de contacto $\left({ }^{6,7}\right)$. También se ha reportado casos de neumonitis y dermatitis $\left({ }^{8}\right)$. La capacidad de formar quistes resistentes (en comparación a los quistes del género Naegleria) en condiciones desfavorables le facilita una amplia distribución $\left({ }^{9}\right)$, así como también la existencia de bacterias -las cuales les sirven de alimento $\left({ }^{10}\right)$ - les permite su desenquistamiento y adaptación al medio.

El objetivo del presente trabajo es determinar la presencia del género Acanthamoeba en fuentes de aguas artificiales y naturales de la Ciudad de Ica, así como identificar los factores asociados que facilitan su presencia en el medio ambiente.

\section{MATERIAL Y MÉTODOS}

Se recolectó 31 muestras de 7 fuentes de aguas naturales (lagunas) y 24 artificiales (pozos, tanques para terapia de rehabilitación, reservorios y cisternas) durante el mes de mayo de 1997, en la ciudad de Ica.

El departamento de Ica se encuentra al Sur de Lima, su capital es la ciudad de Ica, que está situada en la parte central de la costa del Perú, a $75^{\circ} 43^{\prime} 24^{\prime \prime}$ de longitud oeste y $14^{\circ} 04^{\prime} 00^{\prime}$ " de latitud Sur. Se encuentra a 402 metros sobre el nivel del mar, rodeada de pampas y arenales. El clima es cálido y seco, con una temperatura anual de $23^{\circ} \mathrm{C}$. De cada fuente se recolectó cinco recipientes de $200 \mathrm{~mL}$ de agua, de igual número de sectores de la periferia y de la parte central de la fuente; fueron obtenidos en el transcurso de la mañana, tanto de la superficie como del fondo de cada una de las fuentes de agua seleccionadas. Se utilizó cucharones de metal y frascos de vidrio estériles, que fueron sumergidos en el agua hasta llenarse por completo; al momento de la recolección se registró el $\mathrm{pH}$ y la temperatura. La manipulación del material se realizó en condiciones asépticas en todo momento.

Las muestras fueron sedimentadas durante 24 horas, a temperatura ambiente. Se eliminó el sobrenadante y se procedió a sembrar $1 \mathrm{~mL}$ del sedimento mediante dispersión sobre dos placas Petri conteniendo Agar Myast (extracto de levadura, extracto de malta y agar-agar) y otras dos conteniendo Agar Napolitano (extracto de levadura, glucosa, cloruro de sodio y agar-agar). 
Luego fueron incubadas a $37^{\circ} \mathrm{C}$ y observadas a los 10 días; para lo cual se extrajo no menos de tres alícuotas de aproximadamente $20 \mathrm{~mL}$ de una suspensión preparada, agregando solución fisiológica en cada placa y removiendo la superficie del agar con un asa metálica estéril; cada alícuota fue colocada entre láminas portaobjeto y cubreobjeto, luego observada bajo microscopio a 100 y 400 aumentos, recorriendo la lámina en su totalidad de extremo a extremo y buscando las formas características de los quistes del parásito (formas redondas o poligonales y doble membrana) (Figuras 1 y 2 ).

Las placas positivas fueron lavadas nuevamente con solución fisiológica, para preparar una suspensión de 500000 quistes por $\mathrm{mL}$, que se inoculó a ratones albinos de la cepa Swiss criados en laboratorio inmunocompetentes, con un peso corporal promedio de $15 \pm 2 \mathrm{~g}$ de peso corporal. Se administró lentamente $1 \mathrm{~mL}$ de suspensión mediante una cánula estéril por vía intranasal.

Los animales fueron vigilados durante 30 días ante la presentación de alguna lesión sospechosa. Posteriormente fueron sacrificados, extrayéndose cerebro, pulmón, intestinos y globos oculares de cada animal, para proceder a cultivarlos, buscando recuperar al parásito.

Las lesiones sospechosas fueron cultivadas nuevamente en Agar Myast y Agar Napolitano a $37^{\circ} \mathrm{C}$ y observados a los 10 días, siguiendo el mismo procedimiento descrito previamente.

\section{RESULTADOS}

De las 31 fuentes de agua estudiadas, en 11 $(34,4 \%)$ se aisló formas quísticas con las características del género Acanthamoeba, las mismas que fueron confirmadas como tales por la Dra. Gosvinda Visvesvara en el Centro de Control de Enfermedades de Atlanta, Georgia, Estados Unidos. No se identificó las especies, debido a que el laboratorio mencionado había descontinuado los exámenes isoenzimáticos necesarios para este fin.

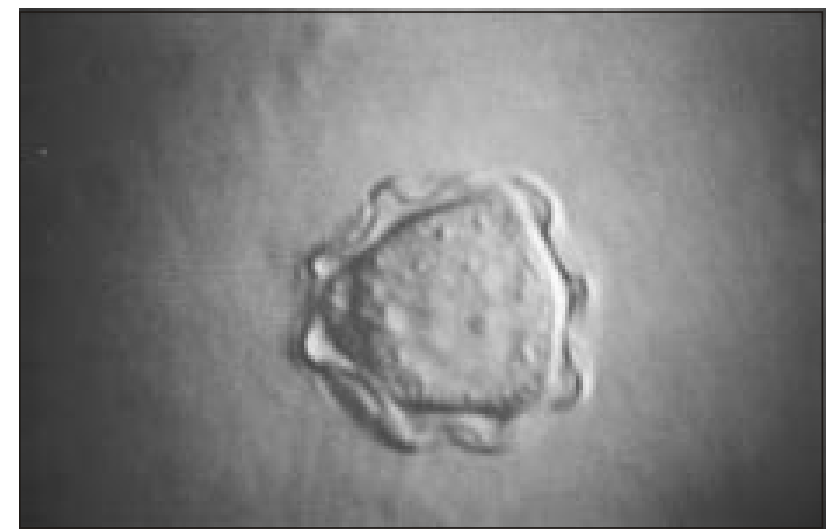

Figura 1.- Quiste de Acanthamoeba sp. con solución de lugol (visión tridimensional, 1000X).

De las 11 muestras positivas, 6 fueron aisladas de fuentes naturales y 5 de fuentes artificiales, mientras que entre las muestras negativas sólo una provino de fuente natural y las otras 19 provinieron de aguas artificiales intradomiciliarias o del hospital local (Tabla 1). Estos resultados permiten obtener un $\mathrm{OR}=22,8$, para la exposición de fuentes naturales de agua, como potencial causante de la infección (límite de confianza $\left.95 \% 1,83-642,55, \mathrm{X}^{2}=7,83\right)$.

El rango de $\mathrm{pH}$ de las muestras positivas fluctúa entre 5 y 7 (media $=6,18$ y DS $=0,6132$ ) y el rango de temperatura de 23 a $27^{\circ} \mathrm{C}$ (me-

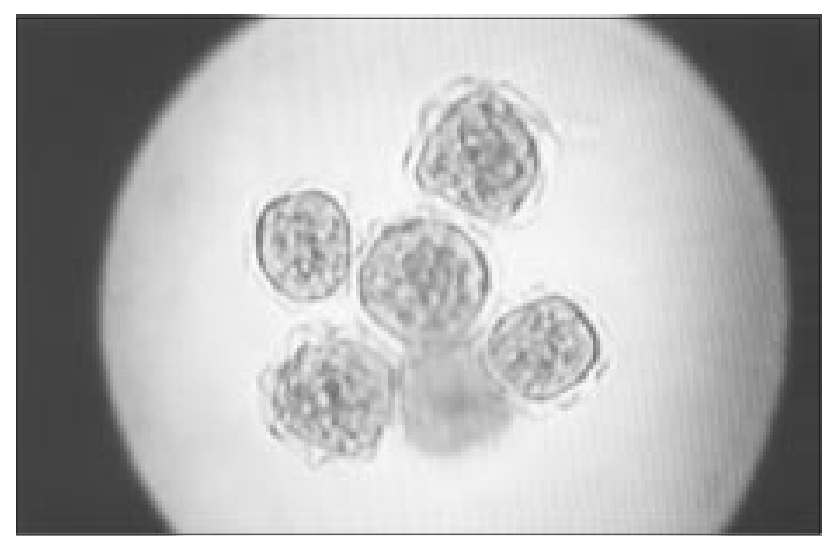

Figura 2.- Quistes de Acanthamoeba sp. con solución de lugol (400 aumentos, amplificada). 
Tabla 1.- Resultados del cultivo según el tipo de fuente de agua.

\begin{tabular}{lrrrrrr}
\hline Fuente & Pos & $\%$ & Neg & $\%$ & Total & $\%$ \\
\hline Natural & 6 & 85,7 & 1 & 14,3 & 7 & 100,0 \\
Artificial & 5 & 20,8 & 19 & 79,2 & 24 & 100,0 \\
Total & 11 & 35,5 & 20 & 64,5 & 31 & 100,0 \\
\hline
\end{tabular}

dia $=24,78$ y $\mathrm{DS}=1,6157)$, no observándose diferencia significativa con respecto a las muestras que resultaron negativas (Tablas 2 y 3 ).

De las 11 muestras positivas que fueron inoculadas en ratones, una mostró actividad patógena, produciendo queratitis en el ojo izquierdo del animal; ella fue aislada a partir de un reservorio y la cepa recuperada mediante cultivo de hisopado corneal y del globo ocular, luego de sacrificar al animal.

\section{DISCUSIÓN}

El género Acanthamoeba fue observado en $35,5 \%$ de un total de 31 muestras revisadas de fuentes de aguas naturales y artificiales (tanques, pozos, reservorios, lagunas) en la ciudad de Ica. Este hallazgo es considerado bajo, comparado con los estudios del Instituto Nacional de Salud

Tabla 2.- Valores de pH según el resultado del cultivo.

\begin{tabular}{lcc}
\hline Resultado & Media & DS \\
\hline Positivo & 6,2 & 0,6132 \\
Negativo & 6,1 & 0,7681 \\
Total & 6,1 & 0,7180 \\
\hline
\end{tabular}

en 1996, en la ciudad de Piura, en donde se revisaba 27 muestras, las cuales incluyen 16 muestras de ríos, 7 de piscinas, 1 de tierra y 3 de tanques. Acanthamoeba fue observada en el $100 \%$ de las muestras revisadas $\left({ }^{11}\right)$. De Jonckheere, en 1981, señala que Acanthamoeba constituye el $43,6 \%$ de la población amibiana en piscinas y el $43,1 \%$ en océanos, según estudio realizado en varias ciudades de Bélgica, donde se ha reportado casos de amebiasis $\left({ }^{2}\right)$.

En la literatura extranjera existen estudios similares. En 1995, John DT y col. realizaron un estudio en 2016 muestras de agua de río en Oklahoma; las amebas patógenas encontradas fueron Naegleria australiensis (38\%), Acanthamoeba (35\%), Naegleria fowleri (18\%) y amebas Leptomyxid $(9 \%)\left({ }^{13}\right)$.

Los factores químicos importantes en el desarrollo de las amebas son la concentración del ácido sulfúrico, salinidad, el $\mathrm{pH}$ y la temperatura $\left({ }^{13}\right)$.

En el presente trabajo se estudió dos parámetros, la temperatura y el $\mathrm{pH}$, los cuales alcanzan una media de $24,78^{\circ} \mathrm{C}$ y 6,18 , respectivamente. Algunos estudios señalan que existe una correlación importante entre la temperatura y la patogenicidad, hecho que no se evidencia en el presente trabajo $\left({ }^{14,15}\right)$.

Otro aspecto importante es la distribución estacional, en Bélgica, De Jonckheere y col
Tabla 3.- Valores de temperatura según el resultado del cultivo.

\begin{tabular}{lcc}
\hline Resultado & Media & DS \\
\hline Positivo & 24,7 & 1,3521 \\
Negativo & 24,8 & 1,7418 \\
Total & 24,8 & 1,6157 \\
\hline
\end{tabular}


(1981) señalan que existe un mayor porcentaje de aislamientos de Acanthamoeba en primavera que en otoño $\left({ }^{16}\right)$; asimismo, que las condiciones climáticas más favorables para que los parásitos sean infectantes para el ser humano son los meses calurosos del año. En nuestro país, Narváez (1996) reporta 4 casos de amebiasis cerebral primaria, los cuales fueron adquiridos durante el verano, mencionando que otros 9 casos reportados en Australia se presentaron bajos las mismas condiciones climáticas $\left({ }^{12}\right)$.

Sólo una cepa produjo lesión ocular en el ratón; se aisló a partir de aguas artificiales, con temperatura de $25^{\circ} \mathrm{C} \mathrm{y} \mathrm{pH} \mathrm{7;} \mathrm{este} \mathrm{resultado} \mathrm{coin-}$ cidiría con reportes extranjeros, que señalan la existencia de amebas que se desarrollan a temperaturas menores de $37^{\circ} \mathrm{C}$ y que son capaces de causar infección latente, que luego originaría enfermedad en presencia de diversos factores asociados, como por ejemplo inmunosupresión concomitante o traumatismos oculares o cutáneos. Por este motivo, la literatura señala la importancia de considerar a todas las especies del género Acanthamoeba como patógenas $\left({ }^{17}\right)$.

Se concluye que, en este estudio, la presencia del género Acanthamoeba es más frecuente en fuentes de agua naturales en la ciudad de Ica, aunque es necesario realizar un estudio de mayor cobertura para confirmar esta situación. Los rangos de temperatura y $\mathrm{pH}$ no mostraron diferencias entre las muestras positivas y negativas. Aproximadamente $10 \%$ de las cepas aisladas de la ciudad de Ica resultaron patógenas para animales de laboratorio inmunocompetentes, lo que confirma el peligro potencial de la población de la ciudad de Ica de contraer la infección por estos parásitos, así como justifican el reporte periódico de casos positivos en esta localidad.

\section{AGRADECIMIENTOS}

Al Dr. Rito Zerpa por su apoyo en la elboración de las fotografías y a la Srta. Susana Jiménez por su invalorable ayuda que ha hecho posible culminar el presente trabajo.

\section{BIBLIOGRAFÍA}

1. Bos HJ. A case of Acanthamoeba keratitis in the Netherlands. Trans Royal Soc Trop Med Hyg 1981; 75(1): 86-91.

2. De Jonckheere JF. Ecology of Acanthamoeba. Rev Inf Dis 1991; 13 (suppl 5): S 385-7.

3. Rodríguez Zaragoza S. Ecology of free living amoebae. Crit Rev Microb 1994; 20(3): 225-41.

4. Sawyer F. Free-living pathogenic and non-pathogenic amoebae in Maryland soils. Appl Environ Microb 1989; 55(5): 1074-7.

5. Campos P, Cabrera J, Gotuzzo E, Guillén E. Compromiso neurológico en amibiasis de vida libre. Rev Neurol 1999; 29(4): 316-8.

6. Brandt F, Ware D, Visvesvara G. Viability of Acanthamoeba cysts in ophthalmic solutions. Appl Environ Microb 1989; 55(5): 1144-6.

7. Martínez A. Free Living Amebas. Natural History, Prevention, Diagnosis, Pathology and Treatment of Disease. Florida, USA:CRC Press Inc. 1985: 145-8.

8. Martínez A, Visvesvara G. Laboratory diagnosis of pathogen free-living amoebas Naegleria, Acanthamoeba and Leptomyxa. Clin Lab Med 1991; 11(4): 861-72.

9. Martínez A. Infection of the central nervous system due to Acanthamoeba. Rev Inf Dis 1991; 13 ( suppl 5): S 399-402.

10. Tyndall R, Domingue E. Cocultivation of Legionella pneumophila and free living amoebae. Appl Envir Microb 1982; 44(4): 954-9.

11. Instituto Nacional de Salud. Amebas de vida libre (AVL) en la ciudad de Piura. 1996; 2(1): 8.

12. Narváez R. Encefalitis amibiana primaria granulomatosa. Diagnóstico 1996; 35(2): 13-9.

13. John D, Howard M. Seasonal distribution of pathogenic free living amoebae in Oklahoma waters. Parasitol Res 1995; 81(3): 193-201.

14. Pearl M, Visvesvara G, Martínez A, Theodore F, Daggett P, Sawyer T. Naegleria and Acanthamoeba infections: Review. Rev Inf Dis 1990; 12(3): 490-513.

15. Griffin J. Temperature tolerance of pathogenic and nonpathogenic free living amoebae. Science 1972; 178: 869-70.

16. De Jonckheere J. Pathogenic and non-pathogenic Acanthamoeba spp. in thermally polluted discharges and surface waters. J Protozool 1981; 28(1): 56-81.

17. Biddick C, Rogers L, Brown T. Viability of pathogenic and non-pathogenic free living amoebae in long term storage at a range of temperatures. Appl Environ Microb 1984; 48(4): 859-60. 